Partzsch, Henriette (2009) Y una radio emitiendo canciones de posguerra: la voz de Concha Piquer en los poemas de Tatuaje de Verónica Aranda (2005). Iberoromania, 67 (1). pp. 43-60. ISSN 0019-0993

Copyright $(2009$ The Author

A copy can be downloaded for personal non-commercial research or study, without prior permission or charge

Content must not be changed in any way or reproduced in any format or medium without the formal permission of the copyright holder(s)

When referring to this work, full bibliographic details must be given

http://eprints.gla.ac.uk/95131/

Deposited on: 18 July 2014

Enlighten - Research publications by members of the University of Glasgow http://eprints.gla.ac.uk 


\section{'Y una radio emitiendo canciones de posguerra': La voz de Concha Piquer en los poemas de Tatuaje de Verónica Aranda (2005) ${ }^{1}$}

Para Marina ${ }^{2}$

La joven poeta Verónica Aranda (Madrid, 1982) ganó en 2005 el VIII Premio de poesía joven "Antonio Carvajal" con un libro cuyo título remite a una voz del pasado todavía muy presente en el imaginario cultural de los españoles. “Tatuaje" $(1941)^{3}$ de Rafael de León y Manuel Quiroga es una de las canciones más conocidas del repertorio de Concha Piquer (1908-1990), la llamada reina o aun emperatriz de la copla ${ }^{4}$, que celebró sus mayores éxitos en la España de los años 40 y 50. A primera vista (y sobre todo desde el exterior de España) ese homenaje puede parecer algo peregrino. No obstante, el texto de Aranda es sólo uno de los últimos eslabones de toda una serie de obras que utilizan y se inspiran en la voz de la cantante; pero, como veremos, Tatuaje lo hace desde planteamientos muy diferentes a por ejemplo el poema "Conchita Piquer" de Una educación sentimental (1967) $)^{5}$ de Manuel Vázquez Montalbán (1939-2003) o bien El cuarto de atrás (1978) ${ }^{6}$ de Carmen Martín Gaite (1925-2000). Es pues preciso relacionar (y como veremos, sobre todo contrastar) los poemas de Tatuaje con la tendencia actual de volver sobre el pasado español reciente y ya no tan reciente, muchas veces en vista de su puesta en narración ${ }^{7}$. La conside-

1 Verónica Aranda, Tatuaje, Madrid: Hiperión, 2005.

2 Le agradezco a mi colega Ricardo Fernández sus sugerencias, observaciones y críticas, siempre pertinentes.

3 Fue la canción de mayor recaudación del año (Vázquez Montalbán, Cancionero general del franquismo 1939-1975, Barcelona: Crítica, 2000, p. XXIII).

4 Terenci Moix utiliza este título superlativo para la cantante en su libro Suspiros de España. La copla y el cine de nuestro recuerdo, Barcelona: Plaza y Janés, 1993; explica su procedencia en la página 58.

5 Manuel Vázquez Montalbán, Una educación sentimental, Barcelona: El Bardo, 1967, pp. 17-20. Citaré por José María Castellet, Nueve novísimos poetas españoles, Barcelona: Ediciones Península, 2001, pp. 59-62.

6 Carmen Martín Gaite: El cuarto de atrás, Barcelona: Destino, ${ }^{18} 2001$.

7 Dos ejemplos de esta actitud, destacados por su éxito considerable, son la serie televisiva ;Cuéntame como pasó! (TVE1, 2001-) y la novela (de investigación) histórica Soldados de Salamina de Javier Cercas (2001). 
ración de ambos aspectos, es decir, el estudio de la función de las referencias intertextuales en comparación con sus antecedentes y la reflexión acerca del efecto que produce el uso de elementos que pertenecen de manera casi tópica a un pasado muy bien delimitado, nos permitirá situar los poemas de Aranda en su especificidad en el entramado de "emoción, localización y nostalgia" que resulta tan importante para la cultura española actual $^{8}$.

Las voces de la postguerra y su interpretación: Concha Piquer, Vázquez Montalbán y Martín Gaite

Los principios de la carrera de Piquer se desarrollan en el mundo del cuplé, tan característico para la incipiente cultura de masas del primer tercio del siglo $\mathrm{XX}^{9}$. Descubierta muy joven en Valencia, Piquer debuta en 1922 con mucho éxito comercial en Nueva York para volver en 1927 a España. Pero no es la imagen de la cupletista la que entrará en la memoria colectiva española, como subraya Terenci Moix: "Las fotografías de aquella Píquer frívola, excéntrica, constituyen una revelación para quienes la recordamos con los atributos de señorío y gravedad característicos de su trayecto posterior." ${ }^{10}$ La Piquer que consigue captar de manera duradera la imaginación de sus compatriotas será la intérprete de la canción española después de la Guerra Civil, aún más precisamente su voz que sale de la radio. Con ello, se convierte en una de los cantantes que retrospectivamente proporcionan la banda sonora a la postguerra espanola ${ }^{11}$. La memoria privilegia pues una de las formas más asequibles de su arte en términos económicos ${ }^{12}$, ya que la radio no fue de ninguna manera la única

8 Paul Julian Smith, Spanish Visual Culture. Cinema, Television, Internet, Manchester, New York: Manchester University Press, 2006, passim.

9 Serge Salaün, El cuplé (1900-1936), Madrid: Espasa Calpe, 1990, sobre todo pp. $202-205$.

10 Moix, op. cit., pág. 48.

11 La película Canciones para después de una guerra de Basilio Martín Patino (1971) explora la vida de la postguerra al ritmo de las canciones de la época (Suevia Films, La linterna mágica, MND 1193, DVD). También el Cancionero (1972) recopilado por Manuel Vázquez Montalbán utiliza las canciones de moda para dibujar un mapa de la sociedad durante el franquismo (Vázquez Montalbán, Cancionero general del franquismo 1939-1975, Barcelona: Crítica, 2000).

12 En 1947 había oficialmente 550000 aparatos receptores de radio en España, "la mitad de ellos en Madrid, Barcelona y Valencia" (Armand Balsebre, Historia de la radio en España, vol. II (1939-1985), Madrid: Cátedra, 2002, págs. 142-143). Esta cifra muestra que durante la primera etapa del franquismo también la radio tenía una difusión bastante desigual, debida a "la miseria económica de una gran mayoría de españoles en el periodo de la autarquía, los altos precios de los aparatos receptores, una potencial audiencia masculina con jornadas laborales en los centros urbanos de catorce a dieciséis horas diarias y un sistema publicitario en fase de reconstrucción" (ibíd.). Vázquez Montalbán nos recuerda los medios más arcaicos que la radio sustituirá: "Todavía en los años cuarenta, la insuficiente electrificación de España propiciaba la existencia del vocalista que cantaba por calles y plazas, no sólo de pueblos sino incluso de ciudades, las novedades de los cancioneros repro- 
vía de difusión del canto de Piquer: en colaboración con profesionales del mundo de la canción y del teatro como Antonio Quintero, Rafael de León y Manuel Quiroga monta espectáculos musicales en los escenarios españoles y americanos, actúa en algunas películas, y también se venden discos y partituras para piano de las canciones de su repertorio ${ }^{13}$. Pero contrariamente al espectáculo y al cine - por lo menos antes de la llegada del vídeo - la radio es un medio que permite un alto grado de descontextualización, lo que ni siquiera pueden contrarrestar el fuerte anclaje franquista y la censura a la que están sometidas todas las emisoras de la época: las voces incorpóreas penetran en los más diversos ambientes, sobre todo en el hogar, y al integrarlas en sus respectivos espacios cotidianos los y sobre todo las oyentes se apropian de lo que están escuchando ${ }^{14}$. Se establece así una relación de familiaridad con la radio que potencia el poder emocional de las canciones transmitidas de manera reiterada, un poder de doble filo: "Lo de siempre: la canción aliena y libera."15

Este fenómeno es todavía más significativo en una situación tan difícil y extrema como la que se da durante la inmediata postguerra, caracterizada por la depauperación de la gran mayoría de los españoles y el violento contraste entre el silencio forzado de los vencidos y el discurso omnipresente del franquismo triunfante. En ese contexto la canción folklórica es usada "desde arriba" para vehicular los valores nacionalistas y para ofrecer una apaciguante vía de escape "apolítica" a la lucha cotidiana por la supervivencia, pero no se pueden controlar todos los aspectos de su recepción "desde abajo": las actividades de escuchar y de cantar se pueden transformar también en experiencia catártica, en expresión elíptica y desplazada de lo silenciado y hasta en un espacio de

ductores de las canciones de los espectáculos de moda" (Cancionero, op. cit., p. XIII).

13 La partitura de "Tatuaje. Canción de puerto" costaba por ejemplo 3,50 pesetas, como está indicado en un ejemplar que data probablemente de los años 40 (Ediciones Quiroga, Madrid, Concepción Jerónima 10, teléfono 7579, fechado por el anticuario). Esta publicación se dirige obviamente a las clases acomodadas, ya que su compra presupone tener acceso a un piano, dinero suficiente para pagar clases de música y tiempo de ocio. La radio en cambio puede perfectamente acompañar algunas formas de trabajo, sobre todo en el hogar.

14 Las emisoras apuntan de manera muy consciente a la audiencia femenina: "El rescate de las emisiones femeninas como magazines informativos, literarios y musicales, mitad escuela de estética y mitad consultorio sentimental, constituye una de las estrategias más significativas de la radio comercial del franquismo para fidelizar poco a poco una audiencia femenina que marcará la pauta del consumo de los productos alimenticios y artículos para el hogar en la sociedad preconsumista de los años 50. Las emisiones femeninas de los años 40 serán el vehículo ideal para el ensayo del sistema comercial del patrocinio publicitario y aglutinarán en torno suyo la primera legión de mujeres que en la década de los 50 pasarán las tardes pegadas al receptor para el consumo de dos, tres y hasta cuatro radionovelas diariamente" (Balsebre, op. cit., pág. 156, cursivas del autor).

15 Salaün, op. cit., pág. 205. 
crítica y subversión ${ }^{16}$. Como ha mostrado Silvia Bermúdez, "Tatuaje” se presta especialmente bien a una apropiación transgresora de este tipo, ya que nos lleva al espacio incontrolable y marginado de los puertos nocturnos, donde el deseo puede circular libremente del marinero extranjero a la prostituta, ambos condenados a una búsqueda sin fin, marcados para siempre con el nombre tatuado del objeto de su deseo: "The writings on these bodies, then, subvert the writings of marriage and procreation promulgated by the Francoist regime and create a space of exile where the power of surveillance can be avoided." 17 Al mismo tiempo la evocación de una vida en el umbral de la sociedad, poblada del fantasma de una ausencia (iirrevocable?), tenía que resonar fuertemente en los supervivientes de la guerra; en los años 40 versos como "Y nadie me dice si está vivo o muerto / y sigo en mi duda buscándole fiel” se podían aplicar a las vivencias desgarradoras de muchas españolas $^{18}$.

Si a partir de los años 60 Manuel Vázquez Montalbán vuelve una y otra vez en sus textos (poesía, columnas periodísticas, novela policíaca y ensayo) sobre la cultura popular de la postguerra, con una atención especial a las contribuciones de Piquer y una cierta preferencia por "Tatuaje”, no se trata de una manifestación fácilmente subsumible bajo el lema de la nueva sensibilidad camp invocada por José María Castellet en su prólogo a la antología Nueve novísimos poetas españoles $(1970)^{19}$, cuyo primer poema es precisamente "Conchita Piquer"20. El mismo antólogo llama la atención sobre "una intención político-cultural" que subyacería a los poemas de Vázquez Montalbán, y hasta recurre a una "doble interpretación del fenómeno camp" para poder acomodar su escritura poética en el marco de interpretación propuesto en el prólogo ${ }^{21}$. Y tiene razón al notar una tensión entre los poetas antologados: el uso que hace Vázquez Montalbán de la cultura popular no tiene mucho que ver con descontextualizaciones y apropiaciones irónicas y festivas, sino que se inscribe claramente en un proyecto de análisis de la sociedad española contemporánea ${ }^{22}$. Para Vázquez Montalbán, la actitud camp frente a la

16 Helen Graham, "Popular Culture in the 'Years of Hunger'", in Spanish Cultural Studies. An Introduction: The Struggle for Modernity, eds. Helen Graham y Jo Labanyi, Oxford: Oxford University Press, 1995, pp. 237-245; José Colmeiro, "Canciones con historia: Cultural Identity, Historical Memory, and Popular Songs", Journal of Spanish Cultural Studies 4, 1 (2003), pp. 31-45.

17 Silvia Bermúdez, “'Music to my Ears': Cuplés, Conchita Piquer and the (Un)Making of Cultural Nationalism", Siglo XX/20th Century 15, 1-2 (1997), p. 40.

18 Para la letra completa (trascripción de la partitura citada con la ortografía original) véase el apéndice.

19 José María Castellet, Nueve novísimos poetas españoles, Barcelona: Ediciones Península, 2001, p. 29.

20 Ib., pp. 59-62.

21 Ib., pp. 38 y 44, respectivamente.

22 Para una aproximación muy lúcida a ese proyecto véase Colmeiro, art. cit., pp. 3334. Sería interesante estudiar en este contexto la actividades y obras del arte del Grupo Crónica. 
cultura popular tiene claras implicaciones de clase y hasta se opone al esfuerzo de comprensión, como constata en 1972:

El descubrimiento de las huellas subculturales fue mistificado por el campismo y en lugar de servir para la historificación del gusto popular, sirvió para generar una seudoestética snob, ya plenamente gastada. Creo que afortunadamente gastada. Ahora ya podremos volver a esas huellas subculturales con talante de arqueólogos o antropólogos, no con talante de pisaverdes de pequeño salón, enfants gâtés dispuestos a épater le bourgeois o épater le marxiste ${ }^{23}$.

Y es cierto, poemas como "Conchita Piquer" se pueden leer perfectamente como un estudio de los efectos alienantes producidos por la discrepancia entre la realidad vital de la gran mayoría de los españoles durante la Postguerra y el mundo ilusorio creado en los medios de difusión masiva ${ }^{24}$. Retrospectivamente, es decir en el año 2000, Vázquez Montalbán reconoce esa dimensión de su escritura cuando admite que "[s]e trataba de un ajuste de cuentas con nuestra formación sentimental en la que las canciones asumidas por nuestros mayores desempeñaban un papel importante. Todos teníamos la edad, más o menos, de John Lennon, pero éramos conscientes de que acarreábamos el lastre de una cultura opresiva." 25 Pero la afirmación citada no quiere decir que el intelectual marxista reduzca las complejas relaciones entre cultura popular y medios de comunicación a una simple cuestión de manipulación del "pueblo". "Con todos sus condicionantes" reivindica en 1972 la llamada “canción nacional” (a la que pertenece "Tatuaje”) como "el cauce subcultural legal más apto para representar la historia sentimental de España" ${ }^{26}$ :

Porque, insisto, una canción no es sólo una voluntad creadora y una voluntad programadora. Una canción es una voluntad receptora que cada vez que la canta, cada vez que la "utiliza", lo hace como instrumento expresivo de la propia sentimentalidad. Sólo bajo este prisma adquieren su real significación hitos como No te mires en el río, Tatuaje, Romance de la otra, La guapa, A la lima y al limón [todas canciones interpretadas por Piquer, HP]. Jamás un sentimiento popular ha sabido expresarse mejor que a través de la utilización [énfasis en el texto, HP] de estas canciones, al margen de la voluntad creadora de sus letristas y músicos ${ }^{27}$.

Vázquez Montalbán detecta con lucidez las huellas que dejan las voces subalternas en las versiones de los cantantes famosos de la época, tantas veces repetidas, y esa lucidez repercute en sus poemas. Incluso si privilegiamos la lectura de "Conchita Piquer" propuesta por su autor en tanto "ajuste de cuentas" que

23 Vázquez Montalbán, Cancionero, loc. cit., p. IX. Es significativo que Vázquez Montalbán interprete el "campismo" exclusivamente en términos de clase.

24 Véase Francie Cate-Arries, "Manuel Vázquez Montalbán: Pop Culture, Mass Media, and the Poetic Creation", in Confluencia: Revista Hispánica de Cultura y Literatura, vol. 2, n 1 (Autumn 1986), pp. 21-27, p. 23.

25 Vázquez Montalbán, Cancionero, loc. cit., p. XLIII.

26 Ib., p. XIX.

27 Ib., p. XX. 
nos muestra cómo mediante los discursos oficiales y comerciales se va formando la sociedad franquista, se nota en el poema la fascinación por las canciones evocadas que puede llevarnos a lecturas menos obvias, en búsqueda de las posibilidades transgresivas del material que la radio introduce en las $\operatorname{casas}^{28}$. No obstante, la idea de un ajuste de cuentas se refleja en la distancia crítica que el poema establece entre la instancia enunciativa y los personajes del poema convertidos en objetos de observación, “ellas" y "ellos": los supervivientes de la Guerra Civil que intentan sobrevivir también la miseria y sordidez de la inmediata postguerra. Es el mundo de los padres - no en balde "Conchita Piquer" pertenece a la primera parte de Una educación sentimental, titutada "El libro de los antepasados" - que moldea la infancia del hijo, con cuya presencia soñadora termina el poema:

ellas

llenaban entonces hasta los bordes el plato

del hijo que soñaba imposibles enemigos desconchados

en la pared pintada por la madre

con un cubo de cal y polvos mágicos

en primavera,

azules $^{29}$.

Pero nos interesa ahora menos la existencia de azur poético en las paredes de un banal piso en un barrio obrero que la sugerencia de un mundo vivencial bien diferenciado según el género de sus habitantes, un fenómeno conscientemente reforzado desde las estructuras franquistas ${ }^{30}$ : "ellos" vuelven al anochecer del

28 Esta alternativa la desarrolla de manera magistral Bermúdez, op. cit., p. 42: "From the outset, the poem exposes two countervailing tendencies. On the one hand, there is the strong presence of a repressive monolithic ideological system with its degrading humiliation. On the other, the wider world does erupt transgressively into the "safe" space of the homes through the presence of Conchita Piquer and the foreign sounds of the fox-trot. Framed by the rectangular shape of the windows, Conchita Piquer's new songs emerge in Vázquez Montalbán's poem at the juncture where critical decisions must be made between interior and exterior spaces: between "the center," with its imposed laws for the living of everyday life, and the antithetical stances to those laws from "the periphery." The imagery of the crossroads emerging from the poem's window setting - with its suggestion of conflict, doubt, and choice - counterbalances the seemingly linear narrative structure of the poem, with its poetic voice describing the comings and goings of husbands and wives in Francoist Spain." Para una lectura inspirada en enfoques poscoloniales y de género de "No me mires a la cara" y "Ojos verdes", interpretadas por Piquer, véase Mercedes Carboyo Abengózar, "Epitomising the Modern Spanish Nation through Popular Music: Coplas from La Caramba to Concha Piquer, 1750-1990", in Gender and History, vol. 19, n. 3 (November 2007), pp. 419-440. Carboyo Abengózar no discute la version censurada de "Ojos verdes" (véase Moix, op. cit., p. 30.) ni la interpretación de otros cantantes como por ejemplo Miguel de Molina o el hecho de que una version fuera escrita ya en 1935 para Blanquita Suárez (Moix, op. cit., p. 50).

29 Castellet, op. cit., p. 62.

30 Véase al respecto Carmen Martín Gaite: Usos amorosos de la postguerra española, Barcelona: Anagrama, ${ }^{15} 2007$. 
trabajo, "ellas" les esperan en casa, rodeadas de las notas de la canción "Tatuaje”, como insinúa el principio del poema:

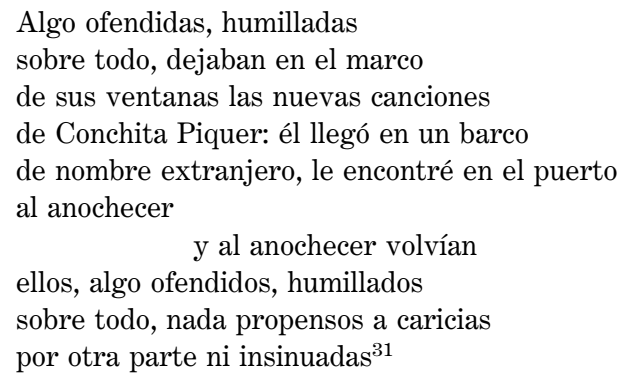

“Tatuaje" se asocia así con el espacio femenino (y hay que repetir que muchas emisiones de la radio se dirigían específicamente a un público de mujeres): la voz de Piquer cantando un amor imposible y nocturno forma parte de un mundo lleno de misterio y pasión adonde huir para olvidar durante la duración de una canción la realidad gris de la vida cotidiana.

Vázquez Montalbán nos presenta ese hecho con la mirada distanciada y supuestamente objetiva de un arqueólogo o antropólogo a la hora de indagar los “condicionantes” de su propia generación. Carmen Martín Gaite, nacida todavía durante la dictadura de Primo de Rivera, nos dará una perspectiva complementaria - si queremos "desde dentro" - con El cuarto de atrás, una novela ensayo autobiográfica y fantástica que propone también una indagación - si queremos antropológica - en la educación sentimental durante la postguerra, pero casi desde el punto de vista de una de las “ellas” del poema de Vázquez Montalbán. En ese texto de 1978 la protagonista y escritora C. desenhebra en una noche de tormenta con la ayuda de un misterioso desconocido los recuerdos de su infancia y adolescencia, según la lógica laberíntica de los sueños y los procesos de memoria. Diferentes textos y recuerdos de la cultura popular de la época, entre ellos una foto de Concha Piquer, desempeñarán una función central en el intento de recuperación y articulación del pasado, como subraya Stephanie Sieburth: "So initially, the path to both content (past experience) and form is blocked for the female protagonist. It will be mass cultural texts (romance novels, mysteries, songs, etc.) which act as the magical agents that permits these aims, seemingly unattainable in the first chapter, to be fully realized."32 Esos estímulos pueden pues alcanzar las zonas más recónditas de la memoria, lo que se ve muy claramente en la evocación de Piquer por la protagonista. C. lleva sus canciones inscritas en su cuerpo porque las solía "utilizar" en tanto "voluntad receptora", como muestra su reacción cuando cita ensimismada una copla y su interlocutor no se da cuenta de la intertextualidad:

31 Ib., p. 59.

32 Stephanie Sieburth: Inventing High and Low. Literature, Mass Culture, and Uneven Modernity in Spain, Durham, London: Duke University Press, 1994, p. 190. 
Podría aclararle que se trata de un texto de la Piquer, o incluso ponerme simplemente de pie; echarme por los hombros un chal negro y, sin mediar otra introducción, apoyarme en la pared y cantarle la copla, que ahora se me viene a la memoria palabra por palabra, y a la garganta, y a los lagrimales, pero me limito a encogerme de hombros y a una pequeña torsión del cuerpo, mediante la cual la espalda me queda descansando contra el borde del sofá, cerca de sus piernas estiradas ${ }^{33}$.

Piquer parece ser de verdad un fantôme $d u$ passé ${ }^{34}$ cuyas reapariciones imprevisibles ni siquiera se pueden exorcizar con la risa y la burla reservadas al kitsch flagrante de las españoladas tópicas, tan siniestramente ligadas a la cultura oficial del Franquismo. La salva la intensidad de su performance que consigue romper la sonrisa oficial, señal de la alegría impuesta por la Sección Femenina a la nueva mujer española. Esa calidad resalta también en el ajuste de cuentas basado en el análisis crítico. Citemos otra vez a C.:

Podría reírme, me ha sonado a copla de Conchita Piquer. Pero, a pesar del desprestigio que ha venido aureolando, con el paso del tiempo, a estos arrebatos de la hembra en celo, de los que yo misma me he burlado tantas veces, todo lo que me vuelva a traer al paladar trasero de la memoria el sabor amargo que diferenciaba aquellas coplas me produce respeto $^{35}$.

Y una vez más es la canción "Tatuaje” que ilustra la fascinación de la voz de Piquer saliendo de la radio, en un pasaje muchas veces citado de El cuarto de atrás:

Y de repente, una ráfaga de sobresalto barría la dulzura [de los boleros de la Bonet de San Pedro, de Machín o de Raúl Abril, HP] y enturbiaba la esperanza: "E.A.J.56, Radio Salamanca; van a escuchar ustedes "Tatuaje", en la voz de Conchita Piquer". Aquello era otra cosa, aquello era contar una historia de verdad; la rememoraba una mujer de la mala vida, vagando de mostrador en mostrador, condenada a buscar para siempre el rastro de aquel marinero rubio como la cerveza que llevaba el pecho tatuado con un nombre de mujer y que había dejado en sus labios, al partir, un beso olvidado. Estaba enamorado de otra, de aquella cuyo nombre se había grabado en la piel, y ella lo sabía, era una búsqueda sin esperanza, pero aquel beso olvidado del marinero que se fue, evocado ante una copa de aguardiente por los bares del puerto, contra la madrugada, se convertía, en la voz quebrada de Conchita Piquer, en lo más real y tangible, en eterno talismán de amor. Una pasión como aquélla nos estaba vedada a las chicas sensatas y decentes de la nueva España ${ }^{36}$.

33 Carmen Martín Gaite: El cuarto de atrás, Barcelona: Destino, ${ }^{18} 2001$, pp. 104-105.

34 C. encuentra su foto en una carpeta marcada con ese rótulo (ib., p. 103). La expresión se presta a una lectura de los procesos de memoria evocados desde las pautas de lo que se suele llamar "hauntology" (para un ejemplo que discute también la película Canciones para después de una guerra véase Jo Labanyi, "History and Hauntology, or: What Does One Do with the Ghosts of the Past? Reflections on Spanish Film and Fiction of the Post-Franco Period", in Joan Ramon Resina (ed.): Disremembering the Dictatorship: The Politics of Memory in the Spanish Transition to Democracy, Amsterdam, Atlanta: Rodopi, 2000, pp. 65-82).

Ib., p. 132.

36 Ib., pp. 134-135. 
En sus intentos de entender tanto los traumas de la sociedad española como la relación que se establece entre ésta y su formación y trayectorias personales respectivas Vázquez Montalbán y Martín Gaite rescatan como testimonios imprescindibles las manifestaciones de la cultura de masas del baúl de los objetos pasados de moda, entre las cuales las canciones de Piquer (y especialmente "Tatuaje") ocupan un puesto de honor. Según su análisis y a pesar de las apariencias "Tatuaje" se podía transformar en refugio e incluso gesto de resistencia porque interrumpía por un breve momento el discurso dominante, pero es preciso subrayar que los dos nunca pierden de vista el contexto histórico concreto a la hora de revisitar ese ejemplo de canción nacional interpretada por una de las grandes estrellas de la cultura española durante el franquismo. Para los dos escritores las emociones cristalizadas alrededor de la canción y la situación política en la que vivieron ellos y sus compatriotas se condicionan mutuamente, y es precisamente esta interdependencia que convierte algunas canciones de la postguerra a partir de la transición en lugar de memoria. En las palabras de Colmeiro: "Martín Gaite's reading suggests that those popular songs were catalysts of forgotten or erased memories, in a double sense: the memory of the collective trauma of the war and its aftermath - during the years of the dictatorship - and the memory of the dictatorship itself - during the years of the political transition."37

Las voces y los ecos después de la transición

Las reflexiones complejas de Vázquez Montalbán y Martín Gaite a partir de las coplas se inscriben por supuesto en una época de profundos cambios de la sociedad española, una época que va desde la transformación de las costumbres y las reivindicaciones de los jóvenes y no tan jóvenes (recuérdese la "Capuchinada" en Barcelona en 1966) durante la última década del franquismo hasta los años de transición después de la muerte de $\mathrm{Franco}^{38}$. Como es bien sabido la estrategia de negociaciones y pactos políticos que lleva finalmente a la instalación pacífica de la monarquía constitucional con democracia parlamentaria influye fuertemente en la construcción pública y social del pasado español. El intento de evitar conflictos a la hora de acercarse a la historia reciente se refleja también en la "utilización" de la canción nacional en textos posteriores, por ejemplo en el ya citado libro Suspiros de España. La copla y el cine de nuestro recuerdo de Terenci Moix (1993). En el prólogo firmado por Román Gubern se puede trazar el esfuerzo de

37 Colmeiro, art. cit., p. 35.

38 Esta periodización coincide con la que defiende Joan Ramon Resina y que está basada en el desarrollo de la economía del mercado: It was the market's implacable logic that pushed Spain, from the sixties on, out of the autarchy and into reformist policies leading up to the Moncloa pact and the Constitution of 1978 ("Short of Memory: the Reclamation of the Past Since the Spanish Transition to Democracy", in Joan Ramon Resina (ed.), op. cit., pp. 83-122, p. 92. 
distanciar la copla de las circunstancias políticas de su producción y primera recepción; se trata de un verdadero esfuerzo porque va en contra de las reacciones espontáneas basadas en la vivencia del franquismo. Gubern explica:

Mi generación ha tenido una relación ambigua con la copla, en razón de su contaminación por el marco ideológico del franquismo. Pero Terenci aclara meridianamente todo posible equívoco. Y hoy sabemos de sobra, después de todo lo que hemos visto, leído o releído, que una forma de expresión popular no debe ser condenada porque haya sido parcialmente instrumentalizada por el franquismo. Ni Góngora, ni Velázquez, ni Dalí, ni Valle-Inclán se salvarían de la quema de esta visión dogmática. La copla es expansión emocional y, desde Platón, sabemos que el lenguaje de las emociones puede parecer ambiguo, pero el tiempo decanta su sentido. Precisamente el paso del tiempo, y desgajadas del kitsch contingente de muchas de sus películas, permite valorar objetivamente el significado de los protagonistas de la copla ${ }^{39}$.

Para “decontaminar" la canción nacional es pues preciso cerrar los ojos ante sus distintas utilizaciones - tan sutilmente analizadas por Vázquez Montalban - para reivindicar una expresión de las emociones que paradójicamente transciende las circunstancias de su desarrollo y cuyo sentido se puede determinar a posteriori. Después del ejercicio de exorcizar tanto la sospecha ideológica como la recriminación de ser un producto kitsch y de mal gusto, las coplas del periodo franquista pueden ser convertidas en pantalla de proyección de la propia nostalgia bajo la forma de una "recuperación de la memoria sentimental de varias generaciones":

De las generaciones que recuerdan el coche con gasógeno, de las que escuchaban Cabalgata fin de semana, de las que reían los chistes de Gila, de las que empezaron a ir de compras y de mirones a Perpignan o a Biarritz y de las que se compraron su primer televisor en color. Ésta es nuestra memoria y como tal ha de ser reivindicada ${ }^{40}$.

Se ve muy bien cómo se sustituye aquí la noción de la canción nacional en tanto lugar de conflicto y negociación de sentido por la utilización metonímica de la canción como elemento a partir del cual se puede articular una visión reconciliadora del pasado, al postular la existencia de una sociedad en la que importaban más las experiencias compartidas de la gente entrenándose para ser consumidores que las diferencias políticas e ideológicas. Huelga decir que la primera persona del plural usada en el texto borra también otras diferencias (de clase y hasta de orientación sexual si miramos de cerca los comentarios acerca del físico atractivo de las cantantes en el prólogo ${ }^{41}$ ). Una vez silenciadas las voces que luchan en y por las canciones ya no hay nada que impida limitar su utilización a la función de estímulo de la memoria de infancia vinculada a una cultura material desaparecida, como deja bien claro Moix:

39 Moix, op. cit., p. 12.

40 Ib., p. 13.

41 Ib., p. 12. En el prólogo los hombres son más bien directores y no tienen físico. Moix desarrolla por supuesto un discurso mucho más queer. 
Para mi generación la copla remite a una infancia de posguerra y se asocia con imágenes concretas: las restricciones, el racionamiento, el estraperlo, los braseros, ciertos objetos, ciertas modas deliciosamente camp, los sonidos de la radio, las varietés en cines de barrio, los cancioneros de peseta en quioscos de compraventa e intercambio ... En la sofisticada resurrección que hoy le presta el compact disc, la copla no regresa como delicia que la nostalgia actualiza o los más agudos intentan reivindicar en términos de calidad, antes bien como un testimonio de la ternura que toda una colectividad necesitó desesperadamente y que las ilustres doña Concha [Piquer], doña Juana [Reina] o doña Imperio [Argentina] repartieron a manos llenas ${ }^{42}$.

Lo que queda es el lado afectivo y políticamente descontextualizado de las canciones, su mensaje de emocionalidad intensa que consigue imponerse aun cuando Moix reconozca en otro momento el malestar que produce el mensaje de la copla, "mensaje ambiguo porque mezcla elementos de extremo conservadurismo - cuando no reaccionarios - con intuiciones progresistas" 43 . Svetlana Boym tiene pues razón cuando subraya la eficacia de la comunicación emocional de las canciones "de siempre": "The music of home, whether a rustic cantilena or a pop song, is the permanent accompaniement of nostalgia - its ineffable charm that makes the nostalgic teary-eyed and tongue-tied and often clouds critical reflection on the subject" 44 . Aun cuando tanto Gubern como Moix quieran evitar lo que perciben más bien como las trampas de la nostalgia que una emoción a lo mejor digna de un interés propio, se desprende de las citas anteriores su cercanía a posibles posiciones nostálgicas, y estas incluyen por supuesto el uso de la ironía camp (en el caso de Moix). La reivindicación de emociones ligadas a la memoria de infancia ocupa ahora el lugar del análisis de la sociedad. El esfuerzo discursivo movilizado para justificar ese cambio de perspectiva muestra que no se trata de un proceso "natural" sino de una toma de posición consciente frente a la representación e interpretación del propio pasado. La propuesta de Moix y Gubern marca un punto muy interesante en el proceso de la memoria colectiva: la mirada analítica y testimonial pierde importancia a favor de la mirada del consumidor de patrimonio cultural. Moix parece intuirlo cuando habla de la "sofisticada resurrección que hoy le presta el compact disc" y de la reivindicación de cantantes como Piquer en términos de calidad, sin considerar el contexto de producción. Serán dos de las opciones para las generaciones posteriores, de los nietos y bisnietos de "ellas" y "ellos" atraídos por el aura de intensidad emocional que los recuerdos de sus padres y abuelos les dan a las canciones de postguerra.

\section{Desfases del deseo: Tatuaje de Verónica Aranda}

Y, con ello, damos el paso a los poemas de Verónica Aranda. La poeta nació en 1982, el año en que el PSOE ganó las elecciones y asumió el gobierno. Aranda

42 Ib., p. 16.

43 Ib., p. 15.

44 Svetlana Boym: The Future of Nostalgia, New York: Basic Books, 2001, p. 4. 
forma pues parte de una generación para la cual las memorias y restos culturales de la postguerra remiten a un mundo no sólo desaparecido sino ajeno a su experiencia personal inmediata, a pesar de que todavía funcione la memoria comunicativa y que los efectos de la guerra y la dictadura, tanto directos como subterráneos, sigan teniendo un fuerte impacto en la sociedad española actual, lo que muestra de manera ejemplar la promulgación de la "Ley de memoria histórica” en 2007 y las discusiones que provocó. Es, pues, probable que la interacción personal de Aranda con las canciones de Piquer esté mediada por la posible presencia en la vida de sus padres y el recuerdo colectivo (que empieza a convertirse en mito) de la voz de Piquer saliendo de la radio en los tiempos de penuria, por un lado, y por las posibilidades de "sofisticada resurrección" de la reina de la copla gracias al disco compacto y los diferentes dispositivos móviles actuales, por otro. Esto significa que canciones como "Tatuaje" pueden tener una incontestable importancia vital, pero se trata de una importancia situada más bien en el nivel individual puesto que para las jóvenes generaciones se va disolviendo la experiencia de la recepción colectiva en un marco compartido. El libro de poemas Tatuaje se inscribe perfectamente en ese nuevo contexto de recepción difusa y personal que lleva a la poeta a trasladar "el lenguaje popular de la copla al lenguaje culto y a mi propio imaginario"45. Con ello se da un paso decisivo que separa la propuesta de Aranda de la de los autores de las generaciones anteriores: a pesar de todas las diferencias de enfoque, tanto para Martín Gaite y Vázquez Montalbán como para Gubern y Moix la copla y su recuerdo son piezas imprescindibles para (re)construir la historia compartida de una época, aunque sus lecturas respectivas luego no coincidan. Aranda en cambio vuelve sobre las canciones de Piquer para indagar en un presente personal, que ciertamente no escapa de los condicionantes (posmodernos) de su propio tiempo y que al mismo tiempo parece hallarse muy lejos del mundo del franquismo. Pero es preciso analizar con más detalle su texto para ver cómo y a qué efecto se utilizan las referencias a la canción de Piquer en Tatuaje, un libro del siglo veintiuno.

Aranda antepone a su libro los primeros cuatro versos de la canción "Tatuaje", a la que dedica la primera parte del poemario - en total una secuencia de veinte poemas -, que vamos a estudiar en lo que sigue ${ }^{46}$. El mecanismo de apropiación del intertexto se establece en el primer poema ${ }^{47}$ con la elaboración del primer verso de la canción. La mirada de la hablante se fija en el barco

45 Citado por "Verónica Aranda recrea la poesía de la copla española en Tatuaje", Diario de Córdoba, 30 de abril de 2006 (http://www.diariocordoba.com/noticias/ noticia.asp?pkid=246657, 21 de julio de 2008).

46

Completa el libro una segunda parte de diez poemas que recogen otras canciones del repertorio de Piquer. Dominan los ritmos de heptasílabos, endecasílabos y alejandrinos sin rima, pero hay excepciones como la composición seguidillesca "Dime que me quieres" (p. 45) con sus hexasílabos y la rima asonante en los versos pares de cada estrofa de cuatro versos.

47 Aranda, op. cit., p. 11. 
"febril, a la deriva" y lo convierte en emblema de la seducción de los viajes, ya que alrededor del mástil se cristalizan recuerdos irreales que sugieren una geografía imaginaria (y tópicamente orientalista: mezquitas azules, Persia, unas indeterminadas rutas de las sedas ...). El poema siguiente ${ }^{48}$ continúa el proceso de transformación y traslado con un rechazo: la figura del marinero ya no servirá de pantalla de proyección para la pasión incondicional de la "hembra en celo", según la expresión de Martín Gaite. El amor por un hombre a perdido importancia (jojalá!) a la hora de cifrar las añoranzas de una mujer, así que la hablante puede declarar que "no buscaba a los rubios marineros, / aquellos extranjeros de frondosos tatuajes" y "[n]o buscaba a esos otros marineros / cuyas promesas se difuminaban / en una despedida inexistente / y siempre se marchaban en las tardes de junio / para no regresar.” El marinero como figura inalcanzable del deseo es así sustituido por la tentación de embarcarse para seguir las rutas de la nostalgia, las rutas del retorno a un sitio mítico que no existe: "Los tatuajes quemaban y esas noches / yo buscaba el camino de regreso hacia Ítaca, / las colinas de Roma, la ciudad de Kavafis / o un barco que zarpara a la isla de Safo." ${ }^{49}$ En la época de movilización global la hablante ya no se queda en la playa (como la bella Lola de la habanera) para esperar el retorno de su amor y vivir a través del hombre el deseo de lo Otro.

De manera consecuente el amor se articula sobre todo en función de esa búsqueda nostálgica, y hasta se puede convertir en gesto teatral que se lleva casi como un accesorio que completa un determinado decorado. Así las ostensibles referencias intertextuales en el poema $\mathrm{XV}^{50}$ (aparecen el mostrador de un bar portuario, el alcohol y el bandoneón que remite al ritmo de tango y el acordeón en "Tatuaje”) sirven más bien para subrayar la distancia con respecto a la desesperación amorosa evocada por los sollozos en la voz de Piquer. El amor ha dejado de ser la experiencia central, es un elemento más de toda una serie evocando una estampa muy reconocible:

Siempre fui por inercia hacia el amor furtivo, aquél de las ciudades portuarias: Buenos Aires con filo de arrabal, La Habana vieja, Lisboa y sus Biralbos misteriosos.

Aquél del bandoneón y las guitarras que tejen un acorde negro y rojo; aquél de los teatros en penumbra con maletas abiertas de tejidos y chales años 20 y nicotina, o el sobrio mostrador donde convergen silencios de licor y penas golfas.

48 Ib., pp. $12-13$.

49 Sería interesante contrastar la nostalgia en Aranda y la evocación de lugares exóticos en sus poemas con la escritura de algunos "novísimos".

50 Aranda, op. cit., p. 31. 
"Nostalgic love can only survive in a long-distance relationship" 51 , una relación a distancia que deja juego a la imaginación gracias a los desfases espaciales y temporales del deseo, como se ve también en los episodios "indios" del libro (poemas V-VII). La voz y los ojos del interlocutor en el poema V crean en la hablante la imagen (de nuevo tópica) de la lejana India, sensual y seductora; "en donde liberaba / mis tigres de nostalgia"52; pero el posterior encuentro con el país significa el desencuentro tanto con el interlocutor como con la India mediada por sus recuerdos: "Fue la misma ciudad y, sin embargo, / la transitamos en distintos tiempos" 53 .

Hasta ahora hemos visto el efecto nostálgico producido por la falta de coincidencia en el tiempo y en el espacio de los objetos del deseo; ahora bien, el eje temporal tiene igual (o más) importancia para la mirada de la hablante. La inmersión total en la búsqueda nostálgica se sitúa en general en el pasado ("y esas noches / yo buscaba el camino de regreso hacia Ítaca" [énfasis de $\mathrm{HP}$ ]) y es contrastado por un presente que permite matizar y cuestionar la posición de la hablante, como por ejemplo en el poema VIII de vuelta de India, si nos fijamos en el orden de la secuencia -. La vuelta a un punto de partida, al lugar de los sueños que habían prefigurado ${ }^{54}$ el viaje muestra la imposibilidad de encontrar un punto estable. Siempre hay "una radio emitiendo canciones de posguerra" 55 , canciones que nutren el deseo por unas experiencias auténticas e intensas y que, al mismo tiempo, hacen tangible su ausencia. La búsqueda de los mitos no lleva a una transformación definitiva sino a la consciencia de un estado carencial, y es el mismo intento de vivir y luego fijar en la memoria momentos de intensidad que conduce a su destrucción:

$$
\begin{aligned}
& \multicolumn{1}{c}{\text { De qué sirve }} \\
& \text { aferrarse a los mitos si he olvidado } \\
& \text { cómo suenan las sedas al rasgarse } \\
& \text { en umbrales de especias y ese tacto } \\
& \text { de la pulpa que dejan las guayabas } \\
& \text { al límite de luz de los balcones }{ }^{56} \text {. }
\end{aligned}
$$

Por consiguiente el poema solamente puede dar fe de la pérdida de la experiencia, de lo que estamos olvidando: ya no se cree en el poder de la poesía para fijar para siempre un momento de epifanía, como lo anhelaba todavía Jorge Guillén en Cántico, y también la reivindicación emblemática "Raso amarillo a

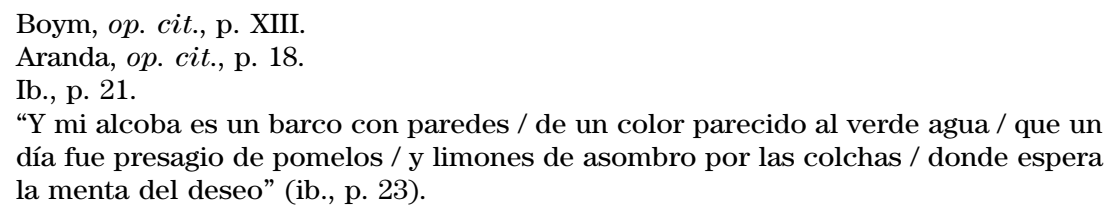


cambio de mi vida."57 del novísimo Guillermo Carnero se vuelve amarga a la hora de pagar el precio por la adherencia incondicional a la búsqueda de la belleza y de lo exótico. En parte se trata de un viejo problema del lenguaje poético que remite a la idea de "hazer nuevo lo que no es" postulada por Herrera en sus Anotaciones a la poesía de Garcilaso ${ }^{58}$, pero es significativo que Aranda lo formule desde el punto de vista opuesto al constatar la hablante que se protege "de un lenguaje excesivo cuyos frutos / siempre acaban secándose a la sombra"59 ¿Cómo evitar que se haga viejo lo que parecía reluciente y significativo? La pregunta es un producto de la lógica que rige nuestras sociedades (pos)modernas. En las palabras de Susan Stewart:

As experience is increasingly mediated and abstracted, the lived relation of the body to the phenomenological world is replaced by a nostalgic myth of contact and present. 'Authentic' experience becomes both elusive and allusive as it is placed beyond the horizon of present lived experience, the beyond in which the antique, the pastoral, the exotic, and other fictive domains are articulated $^{60}$.

Es la pregunta emblemática del viajero, del turista que intenta captar una experiencia al mismo tiempo única y reiterativa (reiterativa porque va en busca de experiencias e imágenes que preceden al viaje, como en nuestro caso por ejemplo "las colinas de Roma, la ciudad de Kavafis") gracias a huellas como fotos, apuntes y recuerdos de viaje. Los poemas de Tatuaje entran en esa dinámica, lo que explica también la presencia de imágenes estereotipadas, ya que la secuencia se acerca a la función del souvenir, es decir, "a sample of the nowdistanced experience, an experience which the object can only evoke and resonate to, and can never entirely recoup." ${ }^{61} \mathrm{El}$ recuerdo de viaje es por supuesto un marcador de nostalgia, esa emoción tan compleja y tan presente en nuestras culturas de fin de milenio ${ }^{62}$. Svetlana Boym la define de manera siguiente: "Nostalgia (from nostos - return home, and algia - longing) is a longing for a home that no longer exists or has never existed. Nostalgia is a sentiment of loss and displacement, but it is also a romance with one's own fantasy." ${ }^{33}$ Los poemas de "Tatuaje" indagan precisamente en este sentimiento de pérdida y desterritorialización: no se trata de reconstruir y reclamar un pasado mejor sino de recorrer espacios imaginarios que se nutren tanto del pasado (literario y personal, es decir, de la hablante) como de la distancia (real e imaginaria).

57 “Guillermo Carnero", "Capricho en Aranjuez”, en Dibujo de la muerte. Obra poética. Ed. de Ignacio Javier López, Madrid: Cátedra, 1998, p. 137.

58 Fernando de Herrera, Anotaciones a la poesía de Garcilaso. Ed. de Inoria Pepe y Jose María Reyes, Madrid: Catedra, 2001, p. 560.

59 Aranda, op. cit., p. 25.

60 Susan Stewart: On Longing. Narratives of the Miniature, the Gigantic, the Souvenir, the Collection. Durham, London: Duke Unversity Press, 1993, p. 133.

61 Ib., p. 136.

62 Véase por ejemploLindaHutcheon: "Irony, Nostalgia, and the Postmodern”, http://www. library.utoronto.ca/utel/criticism/hutchinp.html (29 de julio de 2008).

63 Svetlana Boym, op. cit., p. XIII. 
"Nostalgia is never literal, but lateral" $" 4$ - esta afirmación se puede también aplicar a la exploración de las seducciones y los atolladeros de la añoranza que es Tatuaje. Es un texto cosmopolita cuyo imaginario remite a la crisis de representación de nuestro mundo asimétricamente globalizado, pero se basa en un pretexto culturalmente muy localizado (y parece que poco exportable). Aranda identifica muy bien los dos elementos que unen la canción de 1941 a nuestras obsesiones de hoy: la promesa de mundos lejanos y exóticos (el puerto y el marinero "alto y rubio como la cerveza") y los desfases del deseo como motor de un movimiento continuo que, según parece indicar el último poema de la secuencia ${ }^{65}$, desemboca en la desesperación de la cotidianidad (es decir, el neguit!), por lo menos si se descarta el gran gesto final de la auto-aniquilación. Si seguimos un poco más las sugerencias que nos proporciona el texto se ve claramente que el uso de la canción va más allá del mero hecho anecdótico. Lo que distingue explícitamente la canción de los poemas es el personaje de la hablante, la hablante que se enamora de la promesa de la distancia y hasta parece tener, como los marineros tópicos, un amor en cada puerto. Sin embargo el resultado de su periplo es muy parecido al desenlace de la canción: la mujer tatuada acaba ante una copa de aguardiente, la hablante come, algo más sano, el "pan de la soledad" 66 . Ambos personajes femeninos construyen su identidad a partir de un souvenir muy específico, "su nombre de extranjero, / escrito aquí, sobre mi piel” frente a "cuartillas / y más viejas cuartillas / que hacen alusión a mi nostalgia" "67. El tatuaje y la narración que lo explica consiguen dar un sentido a la identidad de la mujer "de mala vida", mientras que la hablante concede que "[d]e nada sirve rellenar cuartillas"68. Este triunfo del fracaso pasional cantado se puede leer como la figuración de otra añoranza más escondida del texto, la añoranza por la intensidad emocional de la voz de Conchita Piquer y su fuerza comunicativa abarcadora, una posición inasequible para los libros de poemas.

Y con ello, volvemos a la canción "Tatuaje” en la voz de Conchita Piquer como objeto nostálgico emblemático del imaginario español. Hemos visto que el rasgo que caracteriza la canción en la percepción de sus oyentes es su intensidad emocional, catártica para mucha gente en los años de la posguerra. El aura resultante puede transformar "Tatuaje" en un punto de referencia destacado de nostalgia, lo que no quiere decir que haya que borrar automáticamente todos los reparos ante el objeto alrededor del cual se cristaliza el recuerdo y el deseo o ante el contexto en que se inserta. Al fin y al cabo Boym nos recuerda que también existe una nostalgia reflexiva: "It [reflexive nostalgia, HP] reveals that longing and critical thinking are not opposed to one another, as affective memories do not absolve one from compassion, judgement or critical reflection" 69 .

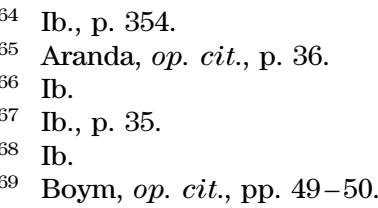


Tatuaje

Canción de puerto

Letra de León y Valerio

Música de Quiroga

(Tpo. de vals)

El vino en un barco de nombre extranjero.

Lo encontré en el puerto un anochecer, cuando el blanco faro sobre los veleros su beso de plata dejaba caer.

Era hermoso y rubio como la cerveza; el pecho tatuado con un corazón.

En su voz amarga había la tristeza, doliente y cansada del acordeón.

(Tpo. de Tango)

$\mathrm{Y}$ ante dos copas de aguardiente sobre el manchado mostrador, él fué contándome entre dientes la vieja historia de su amor.

Mira mi brazo tatuado con este nombre de mujer. Es el recuerdo de un pasado que nunca más ha de volver.

Ella me quiso y me ha olvidado en cambio yo no la olvidé y para siempre voy marcado con este nombre de mujer.

(Tpo. de vals)

El se fué una tarde con rumbo ignorado en el mismo barco que lo trajo a mi; pero entre mis labios se dejó olvidado un beso de amante que yo le pedí.

Errante lo busco por todos los puertos; a los marineros pregunto por él, y nadie me dice si está vivo o muerto y sigo en mi duda buscándole fiel.

(Tpo. de Tango)

$\mathrm{Y}$ voy sangrando lentamente de mostrador en mostrador, ante una copa de aguardiente donde se ahoga mi dolor.

Mira tu nombre tatuado en la caricia de mi piel; a fuego lento lo he marcado y para siempre iré con él. 
Quizás ya tu, me has olvidado en cambio, yo, no te olvidé y hasta que no te haya encontrado sin descansar te buscaré.

\section{(Recitado)}

Escuchame, marinero, y dime que sabes de él; era gallardo y altanero y era más rubio que la miel.

(Cantado)

Mira su nombre de extranjero escrito aquí, sobre mi piel, si te lo encuentres, marinero, dile que yo, muero por él. 